\title{
Espejismos de la modernidad: la Ciudad de México en Los fuereños de José Tomás de Cuéllar
}

\author{
Ana Laura Zavala Díaz \\ Universidad Nacional Autónoma de México \\ alzavalad@yahoo.com
}

\begin{abstract}
Resumen: Publicada en 1883, Los fuereños representa una de las últimas incursiones narrativas del prolífico novelista José Tomás de Cuéllar; en ella, el autor no sólo reflexiona acerca de las condiciones materiales de la Ciudad de México en los umbrales del Porfiriato, sino que analiza, por medio de la mirada de una familia del interior de la República, el estado "moral" de la sociedad mexicana capitalina en pleno proceso modernizador. En sus páginas, Facundo advierte sobre los riesgos económicos y humanos de imponer en un país como México, todavía en construcción, un sistema capitalista basado únicamente en los valores de cambio, en el progreso material.
\end{abstract}

Palabras clave: Ciudad de México; modernización; José Tomás de Cuéllar; Facundo; Porfiriato.

AвSTRACT: Los fuereños, published in 1883, represents one of the last narrative incursions of the prolific writer José Tomás de Cuellar. In this novel, the author not only reflects about the material circumstances of Mexico City during the beginning of the Porfirian era, but also analyzes, through the views of an immigrant family, society's moral status, right as it is going through a critical modernization process. In these pages, Facundo warns about the economic and human risks of imposing in Mexico, a budding country, a capitalist system based solely on the values of change and material progress.

Keywords: Mexico City; modernization; José Tomás de Cuéllar; Facundo; Porfiriato.

Fecha de Recepción: 10 de febrero de 2016.

FeCha de ACeptación: 6 de junio de 2016.

Onocido también con el seudónimo de Facundo, José Tomás de
Cuéllar (1830-1894) fue sin lugar a dudas uno de los principales
novelistas de la segunda mitad del México decimonónico. Durante ese 
periodo, como muchos otros de sus contemporáneos, Cuéllar participó activamente en el movimiento literario y cultural liderado por Ignacio Manuel Altamirano, una vez restaurada la República en 1867. En un ambiente de efervescencia reconstruccionista, este último tuvo el acierto de sistematizar y marcar los lineamientos para la proyección de las tan anheladas letras patrias en sus programáticas "Revistas literarias de México (1821-1867)"; en ellas no sólo validó la existencia de una tradición literaria nacional, ${ }^{1}$ sino que también inventarió y estableció el tratamiento de unos cuantos temas que darían forma a ese corpus literario: el paisaje, las costumbres y la historia nacionales. Tales fueron las vetas definitorias de dicho movimiento ilustrado, que hizo del género novelístico uno de sus principales medios de difusión. Gracias a éste, según Altamirano, "los hombres pensadores" de esa época habían logrado "hacer descender a las masas doctrinas y opiniones que de otro modo habría sido difícil hacer que aceptasen" (39). Poderosa arma de adiestramiento ideológico, la novela moderna "[... se colocaba] al lado del periodismo, del teatro, del adelanto fabril e industrial, de los caminos de hierro, del telégrafo y del vapor[, ya que] ella [contribuía] con todos esos inventos del genio a la mejora de la humanidad y a la nivelación de las clases por la educación y las costumbres" (48).

Partícipe de esta utopía letrada, Facundo descubrió en tan productiva y flexible modalidad textual "el vehículo [...] más idóneo para representar y debatir la tensión propuesta por el deseo de lo Nacional”, por la definición de lo "mexicano" (Benítez-Rojo: 189). Así, a partir de 1869 dedicó la mayor parte de sus trabajos creativos a la escritura de una serie de narraciones, donde expuso la necesidad de elaborar "un nuevo entramado cultural, $[\ldots]$ una nueva red simbólica que direccionara $[\ldots]$

${ }^{1} \mathrm{Al}$ respecto, cabría precisar que, en los albores de la República Restaurada, Altamirano escribió estos textos con el objetivo de demostrar "que la literatura [renacía] en nuestra patria" (Altamirano: 33). Con ese fin, "dedicó sus reflexiones liminares a una breve revisión historiográfica con el afán [...] de reconocer un pasado literario glorioso, en el cual ampararse [e insertarse] desde el presente, cuando las nuevas condiciones del entorno parecían augurar un evidente [resurgimiento] de la cultura nacional. De esa forma, el sagaz cronista validó la existencia de un sistema literario mexicano, al mismo tiempo que destacó la imposibilidad de su consolidación por las convulsas circunstancias del país, que obligaron a los escritores a cumplir otras indispensables funciones sociales. Con ello, estableció y legitimó su lugar en dicho campo, así como certificó su participación y la de un grupo de escritores comprometidos con la producción de los enunciados y del imaginario que darían cuerpo a la nación” (Zavala Díaz: 40). 
el horizonte de un imaginario", en función de la cual se re-significarían los espacios de la geografía patria y modelaría el cuerpo de los ciudadanos; en otras palabras, para Facundo, "había que crear la nación; pero, en especial, forjar los actores y escenarios que sirvieran de base para la existencia” de ésta (González Stephan 1994: 110).

Aun cuando algunas de las novelas de su primer ciclo narrativo se sitúan en la provincia mexicana, ${ }^{2}$ Cuéllar erigió como espacio central de sus obras una Ciudad de México que en pocos años transitó de un estado pre-moderno a una modernización desigual, artificiosa, producto más de los deseos progresistas de las clases en el poder, que consecuencia lógica del mejoramiento real de las condiciones materiales del país. Una modernidad de oropel que, para hacerse "visible", se apoyaría en la evidencia arquitectónica, en la construcción de diversas obras públicas, al nivel de lo cual se buscaba representar; en fin, un "modernismo del subdesarrollo" obligado a la postre "a basarse en fantasías y sueños [...], a nutrirse $[\ldots]$ con espejismos y fantasmas y de la lucha con ellos [...; a ser estridente, basto y rudimentario" (Berman: 239). Centro neurálgico de la nación, para Cuéllar, la ciudad sería el epicentro de esa "estridencia", "espacio desde el cual se [articularían] las fuerzas discursivas que [promoverían] el sueño de la modernización” (Ruiz: 81); pero también, micro-cuerpo modélico, donde se leería el estado general del organismo patrio, como intentaré mostrar a propósito del análisis de Los fuereños, una de sus últimas y mejor escritas narraciones.

\footnotetext{
${ }^{2} \mathrm{Al}$ referirse a la narrativa facundiana, Vicente Quirarte distingue dos etapas claramente diferenciadas; de 1871 a 1872 "es la primera serie de La Linterna Mágica; a la década de ochenta corresponde la segunda. La consumación del proyecto liberal en el primer caso; el establecimiento de la paz y el inicio de la riqueza material, en el segundo" (31). Con el título general de La Linterna Mágica, la citada primera serie constó de seis obras: Ensalada de pollos (segunda edición, corregida y aumentada), Historia de Chucho el Ninfo. Con datos auténticos, dichos e indiscreciones familiares (de las que el autor se huelga), Isolina la ex-figurante (Apuntes de un apuntador), Las jamonas. Secretos intimos del tocador y del confidente, Las gentes que "son asi" (Perfiles de hoy) y Gabriel el cerrajero o las hijas de mi papá. A estos volúmenes se deben agregar: El Pecado del siglo. Novela histórica (Época de Revillagigedo, 1789), de 1869, y Las posadas, cuyo primer testimonio data de 1871. El segundo ciclo, mucho más breve, lo conforman: La Noche Buena. Negativas tomadas del 24 al 25 de diciembre de 1882 (1883), Los fuereños (1883), El divorcio (1883-1884, extensa novela inconclusa), Baile y cochino... (1885) y Los mariditos. Relato de actualidady de muchos alcances (1890).
} 
A diferencia de las novelas que formaron parte de la primera época de La Linterna Mágica, Los fuereños no se proyectó como parte de una serie ni se distribuyó en fascículos para su venta semanal e independiente, sino que sus catorce entregas se insertaron en las heterogéneas columnas del periódico de Filomeno Mata, El Diario del Hogar (1883). ${ }^{3}$ Dadas las restricciones de dicho medio de producción, el autor debió de, por un lado, adecuar su escritura al breve espacio que seguramente le confirieron el redactor en jefe o el cajista del diario; y, por el otro, establecer un diálogo, implícito o explícito, con los contenidos directos, cotidianos, inclusive sensacionalistas, del abigarrado corpus periodístico. De extensión y periodicidad variables, las entregas de Los fuereños aparecieron, así, rodeadas de noticias sobre los adelantos científicos y tecnológicos, médicos e ingenieriles, que poblaron las fantasías de los capitalinos de las últimas décadas del siglo XIx. El asombro de los lectores ante las transformaciones materiales y culturales del momento encontró un correlato en la admiración que domina a los personajes facundianos de esta novela, en la cual se narran las peripecias y descalabros, tanto económicos como morales, de una "inocente", pero pretenciosa, familia de fuereńos que por primera vez se enfrenta al complejo escenario de una Ciudad de México en plena transición modernizadora. En cuanto a esto último, sólo cabría advertir que una serie de cambios personales y contextuales enmarcaron la escritura de las últimas creaciones de Cuéllar, quien, después de diez años de residencia en Washington, capital

${ }^{3}$ Facundo, "Los fuereños", en El Diario del Hogar, t. II, núms. 149, 155, 160, 166, 172, 178, 184, 190, 196, 202, 208, 214, 220 y 226 (11, 18 y 25 de marzo; 1, 8, 15, 22 y 29 de abril; 6, 13, 20 y 27 de mayo; 3 y 10 de junio de 1883), pp. 2-3; $2-3 ; 1-2 ; 2-3 ; 2-3 ; 2-3 ; 2-3 ; 2 ; 2 ; 2 ; 2-3 ; 2-3 ; 2-3$, y 2-3, respectivamente. Unos ańos más tarde, con el mismo título y firma, el autor la incluyó en la segunda serie de La Linterna Mágica, publicada en España (Imprenta y Litografía El Atlántico, Santander, 1890, t. VII, pp. 7-187). En 2012, la edición crítica de esta narración fue incluida en el volumen Obras IV. Narrativa IV. Novelas cortas. El carnaval (1851), Novela por vapor (1869), Las posadas (1871, 1872, 1882, 1892), El hombre-mujer (1872), La Noche Buena [Negativas tomadas del 24 al 25 de diciembre de 1882] (1883, 1890) y Los fuereños $(1883,1890)$. Edición crítica, estudio preliminar, notas e índices de Ana Laura Zavala Díaz, con el apoyo técnico de Coral Velázquez Alvarado y Pamela Vicenteńo Bravo. Edición dirigida por Belem Clark de Lara. México: Universidad Nacional Autónoma de México, Coordinación de Humanidades / Programa Editorial, Instituto de Investigaciones Filológicas / Seminario de Edición Crítica de Textos, 2012 (Nueva Biblioteca Mexicana, 175), pp. 167-284. 
de uno de los países más poderosos en el sector económico, regresó a un México que empezaba "a industrializarse, a depender de la inversión extranjera y a convertirse en una sociedad suntuaria, consumista, basada en la apariencia" (Glantz: 18); en fin, a un México ocupado en construir el espejismo desarrollista, bajo la dirección de los defensores del lema positivista de "paz, orden y progreso". 5

Ahora bien, de acuerdo con María Teresa Zubiaurre, "el sentido que predomina en la novela, y en la ficción en general, es la vista"; es ésta "la verdadera responsable de la organización (subjetiva) del espacio" (23). Ciertamente, es dicho sentido el que impera a lo largo de las páginas de Los fuereños; a través de éste, Facundo intenta re-organizar, clasificar y abarcar la realidad urbana, al mismo tiempo que plasmar críticamente su propio espanto, su íntimo desconcierto ante la realidad nacional que enfrentó a su vuelta al país. En esa dinámica visual, esta familia de fuereños se volverá "todo ojos" (Cuéllar 2012: 198), pues "la presencia de un entorno susceptible de ser captado [... sólo] adquiere significado si alguien lo destaca, si alguien lo relaciona con contenidos precisos o vagos", si alguien, en suma, lo encarna (Bobes Naves en Zubiaurre: 23). Consciente de ello, Cuéllar recurre a dos tipos de personajes para "hacer ver" al lector el espacio citadino: uno, "fijo e inmóvil que presencia una escena o paisaje en movimiento", como los jóvenes pollos y lagartijas que se apostan durante largas horas en la céntrica calle de Plateros; otro, "móvil que avanza ante 'un decorado estático pero complejo", como será el caso de los integrantes del clan provinciano. De igual forma, emplea dos recursos narrativos para insertar significativas representaciones de la urbe: "hablar [o, en este caso, dialogar] (hablar con conocimiento de causa [o no] del objeto a descripción) y, finalmente, actuar

${ }^{4}$ Durante el controversial gobierno de Sebastián Lerdo de Tejada, Facundo fue nombrado segundo y, después, primer secretario de la Legación Mexicana en Washington, cargo al que renunció por cuestiones de salud en los albores de la década de los ochenta (cfr. Sin firma, "Gacetilla. José T. de Cuéllar", en El Diario del Hogar, núm. 167, 19 de abril de 1882, p. 3).

${ }^{5}$ Recuérdese que una vez consumado el triunfo del Plan de Tuxtepec en 1877, Porfirio Díaz ocupó la silla presidencial durante un primer cuatrienio marcado todavía por la inestabilidad política y algunos levantamientos armados. "Defensor" del principio de la "no reelección", el general cedió el mando del país, durante un periodo, a su compadre, el general Manuel González, cuyo régimen impulsó de manera importante el avance mercantil y ferroviario en el país. Sobre los claroscuros de la administración gonzalista, véase Valadés: 65-71. 
en relación con el objeto descrito" (Zubiaurre: 53). El mejor ejemplo de esto lo encontramos en los patriarcas fuereños, dońa Candelaria y don Trinidad, quienes parecieran cumplir únicamente la función de observar, de juzgar desde la óptica del interior de la República, a una Ciudad de México que se presenta bajo el influjo de lo extranjero, en particular de la gran capital del mundo en el siglo XIx: París. De esta suerte, ambos cuestionan con insistencia al señor Gutiérrez, especie de Virgilio capitalino, que los conduce por las principales calles y avenidas de la metrópolis:

-Y dígame señor Gutiérrez -preguntó doña Candelaria-, ¿es de rigor andar en México del brasilete?

—Es lo más cómodo, y los empedrados son tan malos que no sería difícil tropezar de noche. [...]

— ¡Ay, Jesús, María y José! -exclamó doña Candelaria al llegar a la Plaza del Seminario.

- ¿Qué le sucede a usted señora?

-Que me lastima el gas.

- ¿Qué gas?

—Ese blanco del farol, mire usted qué barbaridad.

-Ésa es la luz eléctrica, doña Candelaria.

— ¡Por cierto de su elétrica! Si está de volverse ciego.

—Es una luz hermosísima.

- iQuite usted allá!, qué hermoso va a ser eso, si es peor que un hachón de ocote en las narices. De seguro yo me voy a enfermar esta noche de la vista, señor Gutiérrez. [...]

— ¿Y eso tan grande de fierro que está en el centro? -preguntó don Trinidad. [...]

—Es el Circo Orrin [...].

- ¿Y qué? ¿Circo como todos?

—Es lo mejor que ha venido a México.

-Luego es de extranjeros.

- Sí, señora, de americanos.

-Ya lo oyes, Trinidá; el circo es de extranjeros.

- ¡No te lo he dicho ya!, vas a ver que venir a México hoy, es como si fuera uno a Francia (Cuéllar 2012: 186-189; las cursivas son mías).

Si bien la misión primaria de estos personajes es hablar acerca de lo que miran y con ello posibilitar el engarce no forzado de las descripciones urbanísticas con la narración novelesca (cfr. Zubiaurre: 24), la 
función del señor Gutiérrez, además, es traducir para los fuereños todo aquello que contemplan; más aún, especie de álter ego de Facundo, representa la mirada crítica, encargada de hacer visible la principal paradoja de la incipiente modernidad porfiriana: el progreso científico y tecnológico que ha transformado de manera tan evidente el espacio citadino (ferrocarriles, telégrafo, teléfono, luz eléctrica, etcétera), no guarda relación alguna con los usos y costumbres de sus habitantes. En otros términos, el avance material de la nación no ha servido para el perfeccionamiento ni homogenización de sus integrantes; por el contrario, ha fomentado la proliferación de diversiones y relaciones comerciales que no alientan los comportamientos "colectivos que implican el subyugamiento de la rudeza, de la violencia y de los impulsos espontáneos" (Cruz de Amenábar: 61); no han "domesticado", entonces, la barbarie, según el autor. Al referirse al sistema de transporte público de la Ciudad de México, Gutiérrez afirma:

-En otros países las tranvías ${ }^{6}$ tienen por objeto acortar el tiempo y la distancia, porque el tiempo es dinero, según dicen los yankees, pero entre nosotros no se trata del tiempo.

-No, ¿pues de qué?

- Simplemente de ir sentado.

-No comprendo.

- Pues es muy sencillo, mire usted. En las grandes ciudades, el servicio de las tranvías ha sido trazado en el plano respectivo conforme a las exigencias de la población por los arquitectos de ciudad, y con la intervención del cuerpo municipal que es el encargado del servicio público; en consecuencia, una vez formado el plan de este servicio y trazadas las líneas necesarias que han de proporcionar ahorro de tiempo, acortamiento de distancias y comodidad a los transeúntes, se contrata la obra bajo las bases convenientes, que son por lo general el poder cruzar la población en varios sentidos pero en línea recta, que, como sabe usted, es la más corta. Pero en México, señor don Trinidad, no es la línea recta la que nos preocupa, sino la curva; ésa es nuestra línea, y por la curva vamos a

\footnotetext{
${ }^{6}$ En 1869 , por primera vez, el Diccionario de la lengua castellana registró la palabra tranvía; sustantivo femenino que aludía a un particular tipo de "ferrocarril", en el que los carruajes eran "arrastrados por caballerías". En la siguiente edición de dicha obra publicada en 1884, un año después de la novela de Facundo, el término apareció ya como un anglicismo de género masculino, proveniente de los vocablos: "tram-way; de tram, riel plano, way, vía”.
} 
todas partes. De esto son una prueba las tranvías, divididas en circuitos que, como los anillos de una cadena, se tocan entre sí; de manera que el transeúnte puede llegar a su destino después de haber descrito, en vez de una línea recta, un número 888 (Cuéllar 2012: 181-182).

A lo largo de la historia, la aguda "mirada" de este personaje cobrará mayor relevancia en la medida en que acompañará y reforzará las observaciones críticas del propio narrador. Experimentado escritor de novelas por entregas, Facundo emplea para la formulación de estas últimas uno de los principales recursos del folletín; me refiero, por supuesto, a la introducción de excursos moralizantes, por medio de los cuales se podía alargar todo lo necesario una entrega o alimentar la curiosidad del público al "suspender" el curso de las aventuras de los personajes; pero que también tenían la función de sintetizar las inquietudes y reflexiones del creador ante la realidad histórica. En este sentido, como bien señala Martha Elena Munguía Zatarain, "un rasgo frecuente en la narrativa decimonónica" es "el exagerado peso de la voz narradora, clara proyección del autor, quien aprovecha su autoridad para lanzar [...] juicios éticos, para enseñar o de plano para hacer proselitismo político" (150). Aunque pareciera ajena a la historia, esta voz en realidad representa, en palabras de la investigadora, "una manera de fundar la tensión entre historia y enunciación, [...] es una voz que porta una visión crítica y por ello entra en pugna con el núcleo de la acción referida" (151). En Los fuereños, Facundo utiliza esa "voz" para visibilizar los espacios ciudadanos que entran en conflicto con la representación de una Ciudad de México modernizada. Cabe advertir que esa "voz" no se detiene ya en cuestiones relacionadas con la familia o la educación, preocupaciones que de forma obsesiva rondan las páginas de novelas como Ensalada de pollos o Historia de Chucho el Ninfo, sino en la materialidad de la ciudad, en el mal funcionamiento de su sistema de transporte y de administración, en el deplorable estado de sus calles y monumentos, como se aprecia en el siguiente fragmento:

Efectivamente, la Venus del Zócalo ha llegado a su último grado de desaseo y abandono, como las fuentes y todas las demás obras de ornato, para patentizar a la sociedad y a los extranjeros que e[n] nuestros ediles no existe ese espíritu de nacionalidad y de patriotismo que se afana por manifestar la cultura y la ilustración de la capital de la República. [...] 
Igual servicio de aseo y de conservación requiere la banqueta de mármol so pena de que dentro de algunos meses empiece a deteriorarse por todas partes. [...]

Los fondos de la Ciudad deben pasar a otras manos, vista la inutilidad de los ediles (Cuéllar 2012: 214-215).

Para Facundo, sin embargo, "los elementos móviles de una ciudad, y en especial las personas y sus actividades, son tan importantes como las partes fijas" (Lynch: 10), en tanto que forman parte de ella, la construyen. Como advierte Doreen Massey, "el espacio es [en esencia] producto de las interrelaciones. Se constituye a través de interacciones, desde el inmenso de lo global hasta lo ínfimo de la intimidad [...; y, justamente,] porque el espacio es producto de las 'relaciones', [...] siempre está en proceso de formación, en devenir, nunca acabado" (101-102). En su novela, Cuéllar ilumina, justamente, una serie de tensiones en el establecimiento de dichas "relaciones"; en su tránsito por el espacio urbano, la mirada de estos fuereños refleja la íntima paradoja de una nación escindida entre un "moderno" y amoral centro, la Ciudad de los Palacios, y un interior tradicional, ignaro, "patriarcal"; es decir, entre una "idílica" provincia donde todavía reinan la sencillez de la vida campirana, y un espacio capitalino, en el que los contactos se regulan de acuerdo con las leyes del dinero y el comercio, del ocio y la apariencia. Allí, la utopía modernizadora, para Facundo, sólo ha degenerado en falsas imágenes de progreso y bienestar.

Los miembros más jóvenes de la familia de don Trinidad son quienes mejor "encarnan" esta doble mirada sobre lo nacional y, por esto mismo, resultan las principales víctimas del espejismo citadino. En contraste con sus curiosos y escépticos progenitores, los adolescentes fuereños, en particular Clara y Gumesindo, vienen a la Ciudad de México "bien dispuestos a aceptar lo que [iban] a ver por primera vez, [...] no querian perder sus ilusiones" (Cuéllar 2012: 184; las cursivas son mías). Así, Clara sueña desde su "tierra" con encontrar en la capital "su bello ideal" amoroso, por lo que construye dentro de sí una imagen distorsionada de ese espacio ("La Capital de México tenía un encanto tal y se presentaba a [su] imaginación [...] tan llena de seducción y atractivos", 228), a partir de dos influjos igual de perniciosos de acuerdo con la perspectiva del autor: la amistad de una "mexicana", que la inicia "en los misterios del tocador y de la moda", y la lectura de "algunas novelas francesas, escritas precisa- 
mente para despertar en la imaginación de las jóvenes esa clase de sueños y delirios" (228-229). En cuanto a esto último, cabría señalar que, como varios autores de la época, Cuéllar retomó el tópico quijotesco del carácter nocivo de la lectura, reactualizado en aquel momento en función de un conjunto de presupuestos médicos en boga y ampliamente explotado en textos tanto de índole informativa y clínica como literaria. Para los facultativos, dada su innata fragilidad física y emocional, la mujer era más susceptible que el hombre de agotar sus "fuerzas nerviosas" con "la lectura exagerada y mal elegida" de novelas, acto nocivo que degeneraba en "neurosis más o menos graves", las cuales, a su vez, podrían desencadenar padecimientos hereditarios como la hipocondría, la dipsomanía, la epilepsia o la locura (Olvera: 8-9). De acuerdo con Andrés Ríos Molina, incluso en la explicación de algunas de estas enfermedades consideradas como "producto" de la modernidad, los especialistas sostenían que sólo eran malestares que aquejaban a los miembros de "la clase 'suprema", quienes "las adquirían por imitación o por "la funesta influencia de los libros" (98). En el fondo de estos argumentos seudocientificistas subyacía, sin lugar a dudas, la creencia (y el miedo) de que ciertas narrativas podían "transmitir - como las enfermedades - conductas desviadas del orden" (González Stephan 2005: 60) o generar visiones deformadas de la "realidad"; de ahí la importancia de ejercer cierto control y vigilancia sobre las lecturas que llegaban a las manos de las señoritas mexicanas.

En el caso facundiano, las nociones de la "enfermedad lectora" y de la inclinación hacia la moda, por un lado, se identifican como la etiología de la paulatina "des-naturalización" del personaje femenino, de su "pérdida de la inocencia", que culminará en la soñada Ciudad de México tras ser seducida por Manuelito, un adinerado y cínico joven capitalino. Por el otro, ambas referencias insisten y confirman las alusiones de otros personajes sobre el influjo corruptor del elemento exógeno, en particular de lo francés, en el contexto mexicano. La constante crítica fancundiana a la propensión de la comunidad nacional a imitar usos y costumbres galos, seguramente, estuvo mediada por la invasión francesa al país; sin embargo, la postura del autor ante esta cultura resulta mucho más compleja, si se piensa que él mismo se declaró abiertamente seguidor, casi discípulo, de un autor como Balzac, por ejemplo. ${ }^{7}$ Tal ambivalencia posiblemente

${ }^{7}$ En su conocida novela Ensalada de pollos, el narrador incluye esta significativa apología del novelista francés: "Teníais muchísima razón, monsieur Honorato de Balzac, 
cobre sentido al revisar los elementos particulares que ridiculiza y cuestiona de dicha influencia, los cuales parecieran hablar de una apropiación deficiente, acrítica, improductiva, de modas y hábitos extranjeros, en un medio social que aún no resolvía sus más íntimas contradicciones, mucho menos su identidad en el contexto del fenómeno modernizador. Adoptar en esas condiciones modelos extranjeros "deformaba" no sólo la geografía urbana (en la que, a su vez, se reflejaba el estado general del organismo patrio), sino sobre todo el cuerpo ciudadano, como sucede con Clara y su hermana, quienes tienen que disfrazarse, es decir, vestirse y pintarse "a la francesa", ser otras, para transitar por la Ciudad de México, como les reprocha doña Candelaria:

— ¡Niñas! -exclamó doña Candelaria al ver que sus hijas hacían aquello [pintarse] delante de Gutiérrez-; ¿qué dirá el señor? ¡Habrase visto descaro igual!, ya no se conforman con pintarse, sino que ni siquiera lo disimulan. Dice bien mi marido: estos extranjeros son los que vienen a traernos todas esas costumbres. ¡Vaya usted a ver! ¡Se empeñan mis hijas en ser blancas, cuando ni de dónde heredarlo!, yo he sido prieta toda mi vida, pero eso sí, sólo agua y jabón para mi cara. Dios me libre de andar como payaso (Cuéllar 2012: 185).

Por su parte, Gumesindo, no obstante que es el único de los jóvenes fuereños que no intenta mimetizarse físicamente con la urbe, también sufrirá las consecuencias de construir en la idílica provincia una imagen de la Ciudad de los Palacios, en consonancia con sus anhelos amorosos, así como de mostrarse en ese espacio como un ingenuo charrito ansioso de aventuras, pero que ignora las dinámicas sociales de la fauna capita-

hombre privilegiado, profundo filósofo, gran conocedor de la sociedad, vos que con vuestro escalpelo literario disecasteis el corazón humano; vos que con vuestro talento superior supisteis introduciros en el mundo espiritual, y revelar al mundo pensador los tenebrosos y complicados misterios del alma; teníais razón en pararos a meditar mudo y absorto, y de abismaros en la contemplación de este dédalo de misterios que se llama corazón humano. Prestadme algo de vuestra sublime inspiración, un ápice de vuestro ingenio, una sola de vuestras penetrantes miradas, para contemplar a mi vez a mis personajes, pobres creaciones engendradas en la noche de mis elucubraciones y de mis recuerdos. / Yo también suspiro por el mejoramiento moral, yo también deseo la perfectibilidad y el progreso humano, y escritor pigmeo, lucho por presentar al mundo mis tipos, a quienes encomiendo mi grano de arena con que concurro a la grande obra de la regeneración universal. / De tan alta consideración son las razones que me han obligado a escribir mi Ensalada de pollos" (Cuéllar 2007: 183). 
lina. Su deficiente y artificioso conocimiento de los códigos citadinos lo llevará a la $1^{\text {a }}$ calle de Plateros (hoy un tramo de Francisco I. Madero), donde a la vista de todos confundirá a una meretriz con una "mexicana" decente, de la cual se enamorará. Tal equívoco provocará, a la postre, la pérdida del capital económico del núcleo familiar, pues, ante las peticiones de su amante, el charrito no sólo gastará todos los recursos monetarios que lleva en los bolsillos, sino que también pedirá un préstamo que comprometerá la hacienda de su padre. Más aún, al entrar en contacto con el ambiente prostibulario, con los bajos fondos, el personaje experimentará, al igual que su hermana Clara, una evidente degeneración moral y sentimental, que imposibilitará la restauración del "sano" orden campirano, como expone don Trinidad, padre de los infelices fuereños:

- No había podido apreciar hasta hoy la tranquilidad que se disfruta en medio de las costumbres sencillas, como tampoco había podido figurarme hasta dónde pueden llegar los peligros del lujo y la prostitución de las grandes ciudades. Ya usted lo ve, señor Gutiérrez, Gumesindo era bueno, sencillo, sobrio y honrado. Me lo llevo enfermo, de una enfermedad que acaso no alcanzará a curarle ya ni el campo ni el trabajo. Mis hijas eran modestas y vivían conformes en su pueblo; me las llevo enfermas de ambición, de lujo y de placeres. Clara llora sin cesar, y me espanta su destrucción y su cambio de tres días a esta parte. Nada la consuela, nada la alegra, porque ha dado en que es muy desgraciada. Mi mujer vino contenta, y se vuelve triste y abatida, porque ve a sus hijos desgraciados. Adiós, señor Gutiérrez, adiós (283-284).

Las reflexiones finales del personaje sólo confirman los indicios que desde el primer capítulo ha diseminado el autor sobre la condición amenazante de la ciudad; especie de femme tentaculaire que ya años atrás se había tragado a otro de los hijos de don Trinidad, quien sucumbió al canto de las sirenas capitalinas incitado por unos "estudiantes en vacaciones" en el terruño patriarcal. De acuerdo con las convenciones de género de la época, este personaje se traslada a la Ciudad de México en busca de oportunidades educativas y, más tarde, de una "colocación". A diferencia de sus hermanos, para él la domesticación de la barbarie no se relacionará con el establecimiento de una unión amorosa productiva y civilizatoria, ${ }^{8}$

${ }^{8} \mathrm{Al}$ referirse a las "ficciones fundacionales", Doris Sommer sostiene que "las novelas románticas se desarrollan mano a mano con la historia patriótica de América Latina. 
sino con su inserción en el sistema educativo e intelectual positivista; "para ser otro", para imaginarse como otro, al personaje le da "por los libros", "por [ser] letrado", ruta intelectual por medio de la que se despoja de su antigua identidad, al grado de que su familia "ya ni lo conoce". "[E]l muchacho se ha desnaturalizado y se ha hecho más catrín de lo que yo quisiera" (177; las cursivas son mías), confiesa apesadumbrado don Trinidad, que, al rememorar el hecho, insiste:

- Sea lo que fuere, haga usted cuenta que hemos perdido a Nicolás, apenas nos ha escrito, y le parece que su familia no le honra según como se porta con nosotros. Dice que estamos muy atrasados y que somos payos, a éste [Gumesindo] no lo puede ver porque dice que es un bruto; dice que tiene compromisos políticos y ya está metido con la gente de arriba. Ya lo ve usted, no ha ido a recibirnos. [...]

— ¿Pero está en México? -preguntó Gutiérrez. Acaso no habrá recibido las cartas.

-No lo sé. ¡Sobre que nunca nos escribe! Yo le aseguro a usted que estoy arrepentido, no por él sino por nosotros, de haberle dado gusto. Porque vea usted, lo mismo le ha sucedido a un compadre mío; hizo catrín a un hijo rancherito que tenía, y lo perdió en la Capital; lo envió dizque a estudiar, y se lo malearon hasta el punto que murió el muchacho de mala muerte (177).

En el siglo XIX, de acuerdo con Nil Santiáñez, "la casa establece las raíces de la vida familiar y las ilusiones del ser humano"; representa, así, una entidad "política y moral, un pilar de la clase media, un recinto regido por las convenciones burguesas y por las exigencias de la subjetividad" (281). ${ }^{9}$ En ella, sus habitantes fundan el reino de la intimidad, del individuo, que se opone al exterior amenazante, donde impera la masa, lo colectivo, la multitud. La urbe representa, entonces, por anto-

Juntas despertaron un ferviente deseo de felicidad doméstica que se desbordó en sueños de prosperidad nacional materializados en proyectos de construcción de naciones que invistieron a las pasiones privadas con objetivos públicos. / [.....] La pasión erótica no era ese exceso socialmente corrosivo que debía ser sujeto a disciplina en algunas novelas europeas, sino más bien la oportunidad [...] de mantener unidos a grupos heterodoxos, fueran estos regiones competitivas, intereses económicos, razas o religiones" $(23,31)$.

${ }^{9}$ Para el autor, "vivir en casa, fuera de los lugares públicos [...] significa estar en posesión de un espacio protegido y protector en el cual la presión de la sociedad en el individuo no prevalece" (286). 
nomasia, el espacio contrario, enfrentado al hogar; de forma "estridente" encarna lo externo, "la realidad, materializada en el fenómeno de la muchedumbre, que fluye sin sentido y con excesiva precipitación. Es también el espacio de la especulación inmobiliaria y financiera [..., ] de lo público, de la prosa, el espacio de los hombres, frente al ámbito doméstico, [seguro,] guarecido y sereno, hecho poesía, de las mujeres" (Zubiaurre: 239-240). En Los fuereños, Facundo establece una paradójica analogía entre el espacio íntimo de la casa y la provincia; no es casual, en ese sentido, que quien enuncia el discurso inicie la narración haciendo referencia al desplazamiento de la familia del "interior" campirano a la Ciudad de México en el ferrocarril, emblema central del discurso modernizador porfiriano. El viaje de estos fuereńos reitera, de ese modo, la mencionada dicotomía interior/exterior, pero también el peligro en que se encuentra ese espacio interiorizado ante la irrupción del "caos" urbano, como se insinúa en este diálogo de doña Candelaria: "[...] Con razón le tenía tanto horror al ferrocarril, porque por los ferrocarriles es por donde vienen todas esas cosas, [...] todas esas prostituciones de la mentada civilización de las capitales como México. Bien haya mi pueblo, mi pueblo rabón, pero honrado y tranquilo" (242). En palabras de Hartwig Isernhagen,

la metrópoli es la monstruosa cabeza que, como un tumor canceroso, se asienta en el cuerpo del campo, gobernado desde aquélla. La relación entre ciudad y campo resulta a la vez parasitaria y antagónica: en la ciudad se concentran el lujo y la corrupción, el poder y la explotación, los logros culturales y la charlatanería, que se mezclan confusamente. El campo circundante se $[\ldots]$ expolia, pero, a la vez, hay en él lugar para pequeños reductos en donde reina un orden y que no están expuestos a la desordenada dinámica de la experiencia urbana. En la ciudad se materializan el caos de la anarquía y la destrucción; el campo, en cambio, es el refugio amenazado en el que, silenciosamente y de forma imperceptible, puede, quizá, crearse algo que tenga sentido (Isernhagen en Zubiaurre: 253).

Si bien Facundo muestra esa "anarquía" urbana por medio de la descripción de los excesos etílicos, amorosos y recreativos de los jóvenes fuereños y capitalinos, en realidad un personaje encarnará de forma vívida la sombra del mal que se cierne sobre la pacífica provincia: la prostituta, a la cual el autor identifica como uno de los elementos más negativos de la ciudad y, en otro nivel, del capitalismo. Considerada una patolo- 
gía urbana, la prostitución fue uno de los temas más discutidos en el contexto de escritura de la novela facundiana, dadas sus implicaciones monetarias (es decir, el decrecimiento de la riqueza de los hombres que solicitaban sus servicios) y sanitarias (en particular, por el alto riesgo de contraer sífilis, el gran mal venéreo del siglo XIX). Dos años antes de la redacción de la novela, la preocupación por este "mal" social llevó al gobierno a hacer un "proyecto de Reglamento para la Policía de las Costumbres, [...] en el que [se buscó] dar respuesta a las inquietudes de su época: ¿qué es la prostitución?, su clasificación, inscripción voluntaria y de oficio, formalidades y amonestaciones, multas, atribuciones de los médicos, de los policías, etc." (Núñez Becerra: 84). No obstante los intentos de controlar y fiscalizar a dicho sector de la población, según el discurso cientificista de la época, "esas señoras" seguían enfermando a los organismos masculinos, así como a la geografía misma de la ciudad ya de por sí insalubre y desordenada.

Años después, José Juan Tablada recordaría con cierta nostalgia el lamentable estado de los "sistemas urbanos y cívicos" durante el cuatrienio del general Manuel González, en específico, en el ramo de la prostitución, que parecía haber tomado por asalto la cartografía urbana:

casi cuatro manzanas con sus dieciséis calles correspondientes, cerca del Gran Teatro Nacional y a un costado de la Alameda, eran los dominios de aquella población que con buena voluntad y algo de optimismo, podría llamarse la Citerea capitalina.

Su núcleo lo formaban los dos callejones de López [hoy calles Ramón Corona y López] que atravesaban de la calle de la Independencia a la que entonces se llamaba del Puente San Francisco [actualmente las avenidas Independencia y Juárez....].

La densidad de la población de Citerea era grande en aquellas rúas, pero sus dominios se extendían mucho más allá, diseminándose y llegando hasta el Jardín de Tarasquillo por un rumbo y por el otro hasta el callejón de Santa Isabel [hoy desaparecido...], que entonces desembocaba en el lado oriental de la Alameda.

Durante el día aquellas mansiones gratas al Estagirita, permanecían absolutamente cerradas y en nada se distinguían de las demás, sino quizás en un carácter común a todas ellas, al estar situadas en el piso bajo de las casas o mejor dicho en ser casas de un solo piso...

Pero al caer la tarde, a la prima noche, a la hora de los murciélagos y de las estrellas, todas aquellas habitaciones se iluminaban tanto 
como era posible cuando la luz eléctrica no se había aún generalizado y abrían francamente puertas y ventanas que eran como aparadores donde se ostentaba la mercancía. Las casas de rango se velaban con cortinas transparentes y románticas lámparas a media luz, mientras las inferiores cubrían a medias sus puertas con ciertas celosías verdes que en aquella época usaban sólo esas casas y las cantinas de los arrabales.

[...] Ellas, con holgadas batas o ropones, aparatosos peinados con listones y flores, mantones valencianos, zapatillas bordadas con lentejuelas, de altos y sonoros tacones cuyo resonar sobre las baldosas era uno de los ruidos característicos del vecindario aquel... (69-70).

Aunque la proliferación de aquella actividad fue uno de los problemas de salud pública a los que se enfrentaron las diferentes administraciones porfirianas, lo cierto es que, como muestra la narración de Facundo, las meretrices encarnaron vívida y simbólicamente el lado oscuro de la modernización; su exhibición en los espacios públicos evidenció (y justificó) la necesidad de vigilar y reordenar la topografía urbana, de acuerdo con los principios del discurso médico-higienista que cobró especial relevancia durante esos años. ${ }^{10}$ Su representación en textualidades de diversa naturaleza contribuyó, asimismo, a fijar claros límites entre las conductas sociales consideradas como sanas o patológicas, normales o anormales, gracias a los cuales se diseñaron "los contornos de una alteridad necesaria para la constitución de la conciencia burguesa" (Urías Horcasitas: 373).

Partícipe de ese discurso "progresista" y de clase, Cuéllar no criticó de manera directa el ejercicio de la prostitución, es decir, no propuso la erradicación del oficio más antiguo del mundo, más bien respaldó el confinamiento de las meretrices a un espacio acotado y controlado por el Estado; una zona roja, cuyas murallas invisibles impidieran el desbordamiento de las conductas antisociales, así como la contaminación de la ya de por sí viciosa juventud mexicana (Núnez Becerra: 15$) ;{ }^{11}$ en suma, abogó por una reorganización del espacio urbano que cancelara

${ }^{10}$ Sobre esta cuestión puede verse el iluminador trabajo de Claudia Agostoni, Monuments of progress: modernization and public health in Mexico City, 1876-1910 (2003).

${ }^{11} \mathrm{Al}$ respecto, la autora propone que "las novelas fueron, en general, advertencias prudentes contra los peligros de las pasiones desenfrenadas y exhortaciones acerca de que la civilización moderna exigía sacrificios, es decir, la propagadora de la disciplina erótica” (50). 
la posibilidad de que otro incauto charrito como Gumesindo descendiera a los infiernos del libertinaje y la disipación. Aun cuando en Los fuereños sofrenó su vena catequizante y descriptiva — característica del ciclo narrativo de los setenta- en pro de la creación de una literatura mucho más ágil, eficaz, directa, atractiva y entretenida para el público de ese momento, Facundo no pudo guardar silencio ni dejar que "el curioso lector" sacara sus propias conclusiones ante un asunto de tal importancia para el avance de la nación, por el cual tanto había pugnado; de ahí la extensa disquisición sobre el tema con la que cerró el séptimo capítulo de la historia:

Era ya más de la una de la tarde y los coches de esas señoras habían levantado todo el polvo posible desde la esquina del Portal hasta la Plaza de Guardiola [al oriente de La Casa de los Azulejos]. Las calles principales de la Capital tienen su hora de la misma manera que las personas tienen su cuarto de hora. Ese cuarto de hora es generalmente una debilidad. La Capital tiene la suya que consiste en una especie de transacción escandalosa con las mujeres públicas.

Aconsejamos al extranjero que no juzgue de la moralidad de nuestras costumbres ni de nuestros hábitos religiosos por el cuadro que le ofrecen las calles de Plateros los domingos y fiestas de guardar entre las once y una y media.

Simones más o menos desvencijados y ridículos ocupados exclusivamente por las prostitutas registradas por la policía, ataviadas con los colores más chillantes y los trajes más escandalosos, emprenden durante dos horas la liza de la prostitución con la sociedad, en una especie de vítor o convite de circo coronado de polvo. Una concurrencia numerosísima se coloca en ambas aceras a todo lo largo de ese hipódromo de yeguas humanas, que aún se atreven a cruzar, con la tranquilidad de la inocencia, algunas señoras y algunas niñas de la buena sociedad. El espectáculo no es nada edificante: coches con mujeres públicas, un público masculino, endomingado y lelo, haciendo alarde de su contemplación estática, sin las pretensiones de pasar por simple curioso. Más bien pretende hacer el oso en manada, lo cual, aunque es nuevo, no es del mejor gusto. En ese público que ha resistido y resiste el apodo de lagartijas, abundan los pollos imberbes, haciendo castillos en el aire, lamiéndose los labios, baboseando los nombres de las mujeres perdidas, y trasmitiéndoselos, para llenar la estadística del vicio e iniciarse en sus misterios por el camino más corto y a la faz del mundo, y para completar cuadro, que tan poco honra a nuestras costumbres, el asunto de contemplar 
prostitutas, se combina con el asunto de poblar la larga fila de cantinas y tabernas que se repiten a cortos trechos en toda la avenida.

A esto ha venido a reducirse aquella vieja costumbre de apostarse en el atrio de las iglesias para ver salir a aquellas señoras, en los tiempos en que todos los mexicanos, sin excepción, oíamos misa, y la misa era la ocupación preferente del domingo. Las mujeres que hoy se llaman esas señoras, no se atrevían a exhibirse en ciertos parajes, ni mucho menos pretendieron jamás llamar la atención en masa, por el lujo, por el número, y por la impunidad de la desvergüenza.

La policía no sólo está en su derecho, sino que tiene el deber de dispersar esa manada, para acabar con un abuso que va formando una costumbre escandalosa, indigna de una ciudad culta y moralizada, y está en su deber, puesto que es un gremio que le pertenece, y del que se ha apoderado a nombre de la moralidad y la salud pública, para evitar el contagio no sólo físico sino moral; para garantía y resguardo de la niñez inocente, de la virtud incauta y de la gente honrada (Cuéllar 2012: 204-207; las cursivas son mías).

Si cada personaje de la novela ocupa un lugar y desempeña una función en la ciudad, las prostitutas parecen extenderse como una nube negra por el mapa urbano; así, mientras que doña Candelaria, don Trinidad y Clara transitan por un Zócalo donde se escenifican las diferencias de clase, y Gumesindo ocupa un espacio en la céntrica calle de Plateros, las prostitutas se desplazan sin pudor por las diferentes latitudes de la metrópolis. Caleidoscópica, la ciudad gonzalista de Facundo ha perdido el centro, la Plaza de la Constitución ya no "despacha inmóvil", ya no es el "núcleo centrípeto" de sociabilización, "centro religioso, histórico, cívico, comercial, político" (Cruz de Amenábar: 49); ${ }^{12}$ en esta ciudad abierta, los transeúntes se encuentran desprotegidos, a merced de sus propias pasiones, de sus fobias y compulsiones. $\mathrm{Al}$ re-crear de este modo el mapa capitalino, Cuéllar hizo que su lector "identificara las nuevas

${ }^{12}$ De acuerdo con Federico Fernández Christlieb: “En México, la ciudad converge en el Zócalo; el pueblo viene al centro y el poder despacha inmóvil. La ruptura consiste pues en que Maximiliano, por primera vez, acarrea consigo el poder nacional a lo largo del Paseo imperial hasta su castillo en la cima del cerro de Chapultepec. [..... Años después, ] Díaz [...] vio materializado un urbanismo que cumplía la función de descentralizar físicamente el símbolo del poder, o mejor dicho, personificarlo de tal modo que el poder fuera con él por donde se encontrara. El General Díaz no sólo mantuvo su residencia en Chapultepec, sino que promovió la urbanización del oeste de la ciudad a tal grado que el Zócalo, otrora céntrico, pasó a ser la parte oriental de la aglomeración. La ciudad se extendió” $(253,256)$. 
situaciones sociales trazadas en [... las] coordenadas urbanas" (Viveros Anaya y Gómez Rodríguez: cx); más aún, le mostró los enormes riesgos económicos y sociales de imponer en un país como México, inacabado, todavía en construcción, un sistema capitalista basado únicamente en los valores de cambio, en el progreso material, en las apariencias. Al hacer este "retrato" el autor actualizó en Los fuereños la preocupación que insufló su amplio ejercicio escritural: la urgencia de definir el rostro de la nación, a partir de la configuración modélica de los espacios y de los cuerpos que dieran existencia a ésta; la ciudad, en ese sentido, aunque amenazante y viciosa, se presenta en esta novela como el centro aglutinador de las fuerzas heterogéneas que atravesaban a la nación, como el único escenario posible en donde seguirla imaginando.

\section{BibLIO-HEMEROGRAFÍA}

Altamirano, Ignacio Manuel. Obras completas XII. Escritos de literatura y arte, 1. Selección y notas de José Luis Martínez. México: Secretaría de Educación Pública, 1988.

Agostoni, Claudia. Monuments of progress: modernization and public health in Mexico City, 1876-1910. Calgary: University Press of Colorado / Universidad Nacional Autónoma de México, Instituto de Investigaciones Históricas, 2003.

Benítez-Rojo, Antonio. "Nacionalismo y nacionalización en la novela hispanoamericana del siglo xIx", en Revista de Crítica Literaria Latinoamericana, núm. 38 (1993): 185-193.

Berman, Marshall. Todo lo sólido se desvanece en el aire. La experiencia de la modernidad. 13a ed. Traducción de Andrea Morales Vidal. México: Siglo XXI Editores, 2001.

Cruz de Amenábar, Isabel. La fiesta: metamorfosis de lo cotidiano. Chile: Ediciones Universidad Católica de Chile, s.a.

Cuéllar, José Tomás De. Obras II. Narrativa II. Ensalada de pollos. Novela de estos tiempos que corren tomada del carnet de Facundo (1869-1870, 1871, 1890). Edición crítica, introducción, notas e índices de Ana Laura Zavala Díaz, con el apoyo técnico de Virginia Mote García. Edición dirigida por Belem Clark de Lara. México: Universidad Nacional Autónoma de México, Coordinación de Humanidades / Programa Editorial, Instituto de Investigaciones Filológicas / Seminario de Edición Crítica de Textos, 2007 (Nueva Biblioteca Mexicana, 166). 
Cuéllar, José Tomás de. Obras IV. Narrativa IV. Novelas cortas. El carnaval (1851), Novela por vapor (1869), Las posadas (1871, 1872, 1882, 1892), El hombre-mujer (1872), La Noche Buena [Negativas tomadas del 24 al 25 de diciembre de 1882] (1883, 1890) y Los fuereños (1883, 1890). Edición crítica, estudio preliminar, notas e índices de Ana Laura Zavala Díaz, con el apoyo técnico de Coral Velázquez Alvarado y Pamela Vicenteño Bravo. Edición dirigida por Belem Clark de Lara. México: Universidad Nacional Autónoma de México, Coordinación de Humanidades / Programa Editorial, Instituto de Investigaciones Filológicas / Seminario de Edición Crítica de Textos, 2012 (Nueva Biblioteca Mexicana, 175).

Facundo [José Tomás de Cuéllar]. "Los fuereños”, en El Diario del Hogar, t. II, núms. 149, 155, 160, 166, 172, 178, 184, 190, 196, 202, 208, 214,220 y 226 (11, 18 y 25 de marzo; 1, 8, 15, 22 y 29 de abril; 6, 13, 20 y 27 de mayo; 3 y 10 de junio de 1883$)$, pp. 2-3; 2-3; 1-2; 2-3; 2-3; $2-3 ; 2-3 ; 2 ; 2 ; 2 ; 2-3 ; 2-3 ; 2-3$, y $2-3$, respectivamente.

Facundo [José Tomás de Cuéllar]. Los Fuereños y La Noche Buena [Negativas tomadas del 24 al 25 de diciembre de 1882]. Santander: Imprenta y Litografía El Atlántico, 1890 (La Linterna Mágica, Segunda época, VII).

Fernández Christlieb, Federico. "La influencia en el urbanismo de la Ciudad de México: 1775-1910”, en Javier Pérez Siller (coord.), México y Francia. Memoria de una sensibilidad común. Siglos XIX-XX. México: Benemérita Universidad Autónoma de Puebla, El Colegio de San Luis, Centro de Estudios Mexicanos y Centroamericanos, 1998: 227-265.

Glantz, Margo. "Presentación” a José Tomás de Cuéllar, Las jamonas. México: Consejo Nacional para la Cultura y las Artes, 1998 (Lecturas Mexicanas. Cuarta Serie): 9-18.

González Stephan, Beatriz. "Escritura y modernización: la domesticación de la barbarie", en Revista Iberoamericana, núms. 166-167 (1994): 109124.

González Stephan, Beatriz. "La in-validez del cuerpo de la letrada. La metáfora patológica”, en Revista Iberoamericana, vol. LXXI, núm. 210 (2005): 55-75.

Lynch, Kevin. La imagen de la ciudad. 3a edición. Versión castellana de Enrique Luis Revol. Barcelona: Editorial Eduardo Gili, 1998 (Colección Punto y Línea).

Massey, Doreen. "La filosofía y la política de la espacialidad: algunas consideraciones”, en Leonor Arfuch (comp.). Pensar en este tiempo. Espacios, afectos, pertenencias. Buenos Aires: Paidós, 2005: 101-127.

Munguía Zatarain, Martha Elena. "Cuentos del General y Noche al raso. La fundación de una poética del cuento mexicano", en Rafael Olea Franco (edit.). Literatura mexicana del otro fin de siglo. México: El Colegio de 
México, 2001: 145-155 (Cátedra Jaime Torres Bodet. Serie Literatura Mexicana, 6).

NúÑez Becerra, Fernanda. La prostitución y la represión en la Ciudad de México (siglo XIX). Prácticas y representaciones. Barcelona: Editorial Gedisa, 2002 (Biblioteca Iberoamericana de Pensamiento).

Olvera, José. "Discurso pronunciado en la sesión del día 15 de julio de 1895. La epilepsia y la histeria, neurosis hereditarias y degenerativas. ¿¿Deben considerarse impedimento para el matrimonio?", en Concurso Cientifico. Academia de Medicina. México: Oficina Tipográfica de la Secretaría de Fomento, 1895: 6-15.

Quirarte, Vicente. "Usos ciudadanos de José Tomás de Cuéllar", en Margo Glantz (coord.). Del Fistol a la Linterna. Homenaje a José Tomás de Cuéllar y Manuel Payno en el centenario de su muerte. México: Universidad Nacional Autónoma de México, Coordinación de Humanidades, Dirección General de Publicaciones, 1997: 29-39 (Al Siglo XIX. Ida y Regreso).

Ríos Molina, Andrés. La locura durante la Revolución Mexicana. Los primeros años del manicomio general de la Castañeda, 1910-1920. México: El Colegio de México, Centro de Estudios Históricos, 2009.

Ruiz, Bladimir. "La ciudad letrada y la creación de la cultura nacional: costumbrismo, prensa y nación”, en Chasqui; Revista de Literatura Latinoamericana, vol. XXXIII, núm. 2 (2004): 75-89.

SANTiáÑEZ, Nil. Investigaciones literarias. Modernidad, historia de la literatura y modernismos. Barcelona: Editorial Crítica, 2002.

Sin firma. "Gacetilla. José T. de Cuéllar", en El Diario del Hogar, núm. 167 (19 de abril de 1882): 3.

Sommer, Doris. Ficciones fundacionales. Las novelas nacionales de América Latina. Traducción José Leandro Urbina y Ángela Pérez. Bogotá: Fondo de Cultura Económica, 2004 (Colección Tierra Firme. Serie Continente Americano).

Tablada, José Juan. La feria de la vida [1937]. México: Consejo Nacional para la Cultura y las Artes, 1991 (Tercera Serie. Lecturas Mexicanas, 22).

Urías HorCasitas, BEATriz. "Locura y criminalidad: degeneracionismo e higiene mental en el México Posrevolucionario 1920-1940”, en Claudia Agostoni y Elisa Speckman Guerra (edits.). De normas y transgresiones. Enfermedad y crimen en América Latina (1850-1950). México: Universidad Nacional Autónoma de México, Instituto de Investigaciones Históricas, 2005: 347-383 (Serie Historia Moderna y Contemporánea, 43).

Valadés, José C. El porfirismo. Historia de un régimen. El crecimiento. México: Editorial Patria, 1948. 
Viveros Anaya, Luz América e Irma Elizabeth Gómez Rodríguez. "Estudio preliminar" a José Tomás de Cuéllar. Obras VI. Narrativa VI. Las jamonas. Secretos intimos del tocador y del confidente (1871, 1891). Edición crítica, notas e índices de L. A. V. A. e I. E. G. R. Edición dirigida por Belem Clark de Lara. México: Universidad Nacional Autónoma de México, Coordinación de Humanidades / Programa Editorial, Instituto de Investigaciones Filológicas / Seminario de Edición Crítica de Textos, 2011: LXI-CXXVII (Nueva Biblioteca Mexicana, 172).

Zavala Díaz, Ana Laura. "El Correo de México (1867): hacia la fundación de la república de las letras", en Claudia López Pedroza y Juan Pascual Gay (edits.). Literatura y prensa periódica. Historia de una intimidad. México: El Colegio de San Luis, Universidad Nacional Autónoma de México, Instituto de Investigaciones Filológicas, 2014: 25-47.

Zubiaurre, María Teresa. El espacio en la novela realista. Paisajes, miniaturas, perspectiva. México: Fondo de Cultura Económica, 2000 (Lengua y Estudios Literarios). 